\title{
UM ESTUDO REFLEXIVO \\ DA PRODUÇÃO CIENTÍFICA \\ EM CAPITAL INTELECTUAL
}

\section{A REFLEXIVE STUDY OF ACADEMIC PRODUCTION ON INTELLECTUAL CAPITAL}

\author{
ALESSANDRA VASCONCELOS GALLON \\ Doutoranda em Engenharia de Produção pela Universidade Federal de Santa Catarina (UFSC). \\ Centro Socioeconômico, Caixa Postal 476, Campus Universitário - Trindade - Florianópolis - SC - CEP 88010-970 \\ E-mail: alegallon@terra.com.br \\ FLÁVIA CRUZ DE SOUZA \\ Mestranda em Administração pela Universidade Federal de Santa Catarina (UFSC). \\ Centro Socioeconômico, Caixa Postal 476, Campus Universitário - Trindade - Florianópolis - SC - CEP 88010-970 \\ E-mail: flavia_c_souza@hotmail.com \\ SULIANI ROVER \\ Mestranda em Contabilidade pela Universidade Federal de Santa Catarina (UFSC). \\ Centro Socioeconômico, Caixa Postal 476, Campus Universitário - Trindade - Florianópolis - SC - CEP 88010-970 \\ E-mail: sulianirover@yahoo.com.br \\ SANDRA ROLIM ENSSLIN \\ Doutora em Engenharia de Produção pela Universidade Federal de Santa Catarina (UFSC). \\ Coordenadora do Programa de Pós-Graduação em Contabilidade da Universidade Federal de Santa Catarina. \\ Centro Socioeconômico, Caixa Postal 476, Campus Universitário - Trindade - Florianópolis - SC - CEP 88010-970




\section{RESUMO}

Este artigo apresenta um estudo reflexivo da produção científica em capital intelectual (CI), com base em um estudo bibliométrico e de um mapeamento das publicações reunidas em periódicos nacionais "A" e nos anais do Encontro da Associação Nacional de Pós-graduação e Pesquisa em Administração (EnAnpad) e do Congresso USP. A análise dos 73 artigos sobre CI publicados no período de 2000 a 2006 levou aos seguintes achados: a maioria dos estudos é do tipo prático; o Mackenzie é a instituição de ensino superior (IES) de destaque na produção científica de CI; as obras mais citadas são de Edvinsson e Malone e Sveiby; grande parte das pesquisas concentra a atenção nos usuários internos; a categoria "capital humano, estrutural e de clientes" foi a mais evidenciada nas publicações; o modelo mais utilizado pelos estudos foi o de Edvinsson e Malone; os temas dos estudos brasileiros demonstram paralelismo com aqueles do contexto internacional; confirmou-se o caráter multidisciplinar nos estudos de CI, por meio das tendências identificadas.

\section{PALAVRAS-CHAVE}

Estudo reflexivo; Capital intelectual; Estudo bibliométrico; Mapeamento; Contexto brasileiro.

\section{ABSTRACT}

This paper presents a reflexive study of the scientific production on Intellectual Capital (IC) from a bibliometric study and from a mapping of the results of research published in Brazilian journals classified as " $A$ " by Capes and in the proceedings of the "EnAnpad" and of the "Congresso USP". The analysis of the 73 papers on CI published between 2000 and 2006 yielded the following results: the greater part of the studies is practical in nature; Mackenzie is the most relevant IES [instituição de ensino superior - graduate studies institution] in terms of 
scientific production; citation analysis points to the works by Edvinsson and Malone and Sveiby as the most referenced; most of the research devotes attention to external users; 'human, structural and customer capital' is the most used category; Edvinsson and Malone's model inform most of the studies; there is a parallelism between the topics explored in the Brazilian and in the international contexts; the multidisciplinary character of CI research is confirmed, from the tendencies evidenced in the studies.

\section{KEYWORDS}

Reflexive study; Intellectual capital, Bibliometric study, Mapping, Brazilian context.

\section{INTRODUÇÃO}

De acordo com Kayo, Teh e Basso (2004), o interesse no estudo dos ativos intangíveis (AI) - neste artigo, também referido, intercambiavelmente, como capital intelectual (CI) - tem evoluído nos últimos anos, particularmente em razão da crescente valorização das empresas, a partir de I980, quando emergiu uma diferença significativa entre o valor de mercado e o valor contábil. Segundo Wallman (I996), estima-se que a importância dos AI pode exceder até três ou quatro vezes o valor contábil físico de uma empresa e que o valor médio das companhias abertas que negociam em bolsas de valores pode ser duas vezes o seu valor patrimonial. Dessa forma, considera-se que o CI é o grande impulsionador na manutenção da sustentabilidade da empresa e na criação de seu valor.

A preocupação formal com o CI teve início no contexto organizacional em I994, em que a iniciativa de evidenciação de tais ativos é atribuída à companhia de seguros sueca Skandia, com a publicação do primeiro relatório contemplando CI. Para Carvalho e Ensslin (2006, p. I), "o eixo teórico se seguiu a esta iniciativa prática, tendo a literatura sobre CI emergido em I997, quando da divulgação das pesquisas pioneiras de Brooking (I996), Edvinsson e Malone (I997) e Sveiby (1997 e i998)".

Entretanto, apesar de a literatura contemporânea destacar o CI como uma das fontes de criação de valor às empresas, até o momento não foram desenvolvidas pesquisas no contexto nacional que buscassem investigar o que tem sido desenvolvido na área. Nessa perspectiva, este artigo tem como objetivo analisar a produção científica em CI, por meio de um estudo bibliométrico e de um mapeamento de artigos selecionados. Para tanto, as técnicas de pesquisa utilizadas são a bibliometria e a análise de conteúdo. 
Considerando-se a relevância do CI, tanto na prática organizacional quanto na academia, este estudo busca sistematizar a pesquisa por meio de instâncias legítimas e aceitas pela comunidade acadêmica, por intermédio de técnicas bibliométricas. Leal, Oliveira e Soluri (2003) afirmam que traçar o perfil de determinada área por meio de uma análise bibliométrica não se constitui como pesquisa inovadora, entretanto essa informação não invalida a necessidade de um campo disciplinar se voltar sobre si próprio para, na busca do entendimento de sua trajetória, projetar caminhos futuros. Ressalta-se que, até o momento, não foi identificado nenhum levantamento de tal natureza sobre a área de CI no país.

Diante do exposto, este estudo se justifica por revelar as características das publicações sobre CI, na área em estudo. Um mapeamento dessa natureza se justifica diante da diversidade de estudos que proliferam nesse campo disciplinar, o que vem por ratificar sua natureza multidisciplinar - enfatizada pela teoria: o estudo contribui, assim, para a construção de conhecimento cumulativo sobre CI. Destaca-se, ainda, sua contribuição no sentido de apontar direcionamentos para novos estudos na área.

Além da "Introdução", este artigo apresenta: revisão literária (capital intelectual), definição do método e dos procedimentos da pesquisa, descrição e análise dos dados, e considerações finais.

\section{CAPITAL INTELECTUAL}

Edvinsson e Malone (1998, p. 40) definem o capital intelectual como "a posse de conhecimento, experiência aplicada, tecnologia organizacional, relacionamentos com clientes e habilidades profissionais que proporcionam à empresa uma vantagem competitiva no mercado". Para Antunes (2006), o aparecimento desse conceito conduz à necessidade de aplicação de novas estratégias e de uma nova filosofia de administração, que contemplem o recurso do conhecimento. Nesse contexto, o CI relaciona-se diretamente aos elementos intangíveis resultantes das atividades e práticas administrativas desenvolvidas pelas empresas, em seu esforço para se adaptarem à realidade atual e atuarem nela (BROOKING, I996; STEWART, I998, 200I; PABLOS, 2002; LEV, 200I, 2003, 2004).

Observa-se o interesse crescente pelos recursos de natureza intangível tanto na área empresarial quanto na comunidade científica (PEREIRA; FIÚSA; PONTE, 2004; CARVALHO; ENSSLIN, 2006). As organizações são motivadas, por forças internas e externas, a medir e a gerenciar o seu CI de forma proativa. Internamente, a falta de informação sobre os elementos de CI pode levar a uma inadequada alocação de recursos nas organizações. Antunes (2006) sugere que os gestores, na atualidade, por meio de seus modelos de gestão, façam uso do conhecimento como recurso e, também, como produto ou serviço gerado. Externamen- 
te, ainda é incipiente a informação relevante disponível aos stakeholders sobre os recursos intangíveis. Quanto à relevância das informações contábeis para a tomada de decisão dos usuários externos, Antunes (2000, p. 73) enfatiza que "a urgência em considerar determinados ativos intangíveis na mensuração do real valor da empresa parece ser senso comum".

Rezende (2002, p. 75) aponta que "o reconhecimento da importância estratégica da administração do conhecimento e do capital intelectual das empresas configura-se como a mais recente fase de evolução na gestão da informação". Tinoco e Gondim (2003) afirmam que, com as mudanças de enfoque, as empresas deixam de lado suas preocupações com produtos e serviços, e passam a adotar ações mais criativas e inovadoras, o que as mantém competitivas no cenário atual. Os autores ainda ressaltam ser provável que o bom desempenho em medidas não financeiras tenha reflexos positivos nos resultados financeiros.

Diante do crescente interesse da comunidade empresarial pelos intangíveis, diversos pesquisadores têm realizado estudos sobre esses ativos. Muitos desses autores concentram sua atenção no desenvolvimento de tais recursos nas organizações; outros procuram formalizar os diferentes procedimentos de evidenciação; e há os que buscam identificar e divulgar as diversas formas de execução do gerenciamento desses recursos. Ou seja, a pesquisa sobre CI, que integra o rol dos ativos intangíveis, pode ser caracterizada por uma variedade de visões e interpretações, pois ainda não se desenvolveram escolas dominantes de pensamento, o que teria o resultado positivo de possibilitar uma linguagem comum entre os pesquisadores (KAUFMANN; SCHNEIDER, 2004). Assim, há pouco consenso e muita confusão relacionados à terminologia utilizada para se referir a esses recursos e à definição do conceito de CI. Tal fato pode ser explicado pelo caráter multidisciplinar da área de CI.

No contexto internacional, Marr (2005) aponta nove diferentes perspectivas sob as quais o CI é examinado - economia, estratégia, contabilidade, finanças, evidenciação, marketing, gestão de recursos humanos, sistemas de informação e direito - e sugere a investigação e o mapeamento das diferentes perspectivas disciplinares, com vistas a se proceder a um levantamento dessas diferentes linhas de pensamento. No cenário da perspectiva econômica, Augier e Teece (apud MARR, 2005) oferecem uma visão geral histórica da crescente importância do CI como um direcionador para a inovação e salientam como a natureza do CI oferece grandes desafios para sua gestão e mensuração. No contexto estratégico, Marr e Roos (apud MARR, 2005) apresentam o deslocamento da noção de estratégia de um paradigma baseado em mercado para um paradigma baseado em recursos, fazem uma distinção entre a natureza estática e dinâmica desses ativos e apresentam as ferramentas para a gestão estratégica de CI. Uma outra 
definição de CI é oferecida por Lev, Canibano e Marr (apud MARR, 2005) que, sob uma visão contábil, discutem algumas das dificuldades e inconsistências na maneira como o CI é tratado na contabilidade, apresentando as práticas atuais e as mais recentes regulamentações contábeis para os intangíveis. Sob a perspectiva financeira, Sudarsanam e Sorwar (apud MARR, 2005) discutem a importância do CI para o fluxo de caixa, as oportunidades de crescimento e a seleção de abordagens de avaliação (modelos estáticos e dinâmicos), e apresentam modelos de opções reais de avaliação do CI. No contexto de evidenciação, Mourtisen e Bukh (apud MARR, 2005) discutem como as organizações podem, voluntariamente, declarar o CI, tanto interna como externamente, e apresentam as diretrizes européias para os relatórios de CI. Na perspectiva de marketing, Fernstôm (apud MARR, 2005) discute a importância das marcas, da satisfação do cliente e do relacionamento com os clientes, bem como os diferentes componentes relevantes do CI e como proceder à avaliação e mensuração de tais ativos. Na perspectiva dos recursos humanos, Johansson (apud MARR, 2005) define o CI e aborda várias ferramentas para sua gestão, incluindo os indicadores, a contabilidade e o custeio de recursos humanos. Na perspectiva de sistemas de informação, Peppard (apud MARR, 2005) realiza uma distinção entre dados, informação e conhecimento como ativos organizacionais e o papel dos sistemas de informação e tecnologia na gestão desses ativos, além de apontar como os ativos do sistema de informação devem ser avaliados e como a gestão dos sistemas de informação pode ajudar a transformar o capital humano em capital estrutural. No contexto legal, Cloutier e Gold (apud MARR, 2005) apresentam vários instrumentos e mecanismos legais que as empresas possuem à sua disposição para proteger seu CI. Finalmente, no contexto da propriedade intelectual, Sullivan (apud MARR, 2005) indica como as organizações podem gerenciar, estrategicamente, sua propriedade intelectual para obter valor de negócios.

Assim, argumenta-se a necessidade de investigar e mapear as diferentes perspectivas das pesquisas, que, no contexto brasileiro, lançam o olhar para o CI, conforme manifestadas no conjunto de artigos selecionados para o presente estudo.

\section{MÉTODO E PROCEDIMENTOS DA PESQUISA}

Este artigo caracteriza-se como um estudo descritivo-exploratório. É descritivo por ter como objetivo apresentar os indicadores das publicações científicas da área de CI; é exploratório por buscar conhecer a área de CI no estado em que se 
encontra, com base na pesquisa bibliométrica e no mapeamento feito nas publicações da amostra, o que levará à construção de um panorama sobre a área.

Para a consecução do objetivo proposto, as técnicas de pesquisa utilizadas são a bibliometria e a análise de conteúdo. A bibliometria, para Macias-Chapula (I998, p. I34), "é o estudo dos aspectos quantitativos da produção, disseminação e uso da informação registrada”. Já a análise de conteúdo, utilizada para o mapeamento dos artigos, é definida por Bardin (2004) como um conjunto de técnicas de análise das comunicações, visando obter indicadores que permitam a geração de conhecimentos relativos às condições de produção/recepção dessas mensagens.

O objeto de estudo da pesquisa se embasa nos artigos científicos publicados em periódicos nacionais e eventos científicos da área de administração, ciências contábeis e turismo. Foram selecionadas publicações reunidas em periódicos nacionais com classificação "A" pela Coordenação de Aperfeiçoamento de Pessoal de Nível Superior (Capes) - Organizações \& Sociedade (O \& S), da Universidade Federal da Bahia (UFBA); Revista de Administração Contemporânea (RAC), da Anpad; Revista de Administração de Empresas (RAE e RAE Eletrônica), da Fundação Getulio Vargas (FGV/SP); Revista de Administração Pública (RAP), da FGV/RJ; Revista de Administração da Universidade de São Paulo (Rausp) e Revista Contabilidade \& Finanças, da USP; e Revista Eletrônica de Administração (REAd), da Universidade Federal do Rio Grande do Sul (UFRGS); e nos anais do EnAnpad e do Congresso USP de Controladoria e Contabilidade. Justifica-se a escolha desses eventos por se configurarem como importantes veículos de disseminação da pesquisa sobre CI.

A pesquisa abrangeu os artigos publicados no período de 2000 a 2006 . Observe-se, entretanto, que o Congresso USP teve seu evento inicial em 200I, motivo pelo qual as publicações neste congresso foram consideradas nos anos de 200 I a 2006. O critério utilizado para a coleta dos dados foi baseado na ocorrência das terminologias empregadas para identificar o CI, conforme localizado no título e/ou no resumo dos artigos. Quanto às terminologias utilizadas para identificar esse tipo de capital, encontra-se recorrência dos termos: intangíveis, ativos intangíveis, capital intangível, recursos intangíveis, capital intelectual e propriedade intelectual (GUTHRIE; PETTY, 2000; LEV, 200I; KAUFMANN; SCHNEIDER, 2004). Foram identificados 73 artigos sobre CI no período de análise, sendo 2I em periódicos, 35 no EnAnpad e I7 no Congresso USP.

Com o intuito de conhecer alguns dados demográficos dos estudos sobre CI, na etapa do estudo bibliométrico, investigaram-se: (a) natureza do estudo; (b) fonte de coleta de dados; (c) esfera e nacionalidade das empresas pesquisadas; (d) abordagem metodológica; (e) número de autores por artigo; (f) autores 
mais prolíficos na área de CI; (g) instituição de ensino superior (IES), unidade federativa (UF) e departamento em que os pesquisadores com publicação em CI estão lotados; e (h) obras mais citadas e referências utilizadas.

Quanto à natureza do estudo, os teóricos foram divididos segundo a classificação de Alavi e Carlson (I992), que separa os estudos em três categorias: conceituais, ilustrativos e conceituais aplicados. Os estudos conceituais são aqueles que definem estruturas, modelos ou teorias; os ilustrativos compreendem as pesquisas que funcionam como um guia prático; e os estudos conceituais aplicados combinam algumas características dos estudos conceituais com as dos ilustrativos. Os estudos práticos foram divididos, segundo a classificação de Meirelles e Hoppen (2005), em estudos de caso, pesquisas survey e estudos experimentais - estudos de caso permitem contribuir com o conhecimento dos fenômenos individuais, organizacionais, sociais, de grupo, entre outros (YIN, 2005); pesquisas survey "procuram descrever com exatidão algumas características de populações designadas” (TRIPODI; FELLIN; MEYER, I98I, p. 39); e os estudos experimentais permitem ao pesquisador intervir na característica investigada, além de exercer um controle absoluto sobre o grupo populacional (JUNG, I997).

$\mathrm{Na}$ etapa do mapeamento, uma vez organizados, os 73 artigos selecionados foram submetidos a uma análise de conteúdo detalhada. Ao longo do processo de leitura e interpretação dos artigos, foram identificados alguns focos importantes de análise. Esses focos serviram de base para a elaboração de uma ficha padronizada, para a análise de conteúdo individual de cada artigo. A ficha padronizada contemplou os seguintes tópicos: (a) tipo de usuários para quem o CI é destinado (internos, externos ou internos e externos); (b) tema da pesquisa; (c) categorias empregadas; (d) principais modelos/autores e pronunciamentos norteadores; (e) tendências predominantes; (f) resultados dos modelos de mensuração propostos; (g) resultados das pesquisas empíricas; e (h) recomendações sugeridas nos estudos.

Cumpre esclarecer alguns pontos importantes: (i) nem todos os artigos se prestaram a fornecer todas as informações referentes aos itens listados acima; (ii) como, até o momento, não foi identificado nenhum levantamento de tal natureza sobre CI, no contexto brasileiro, os enfoques e as categorias foram elaborados pelos autores deste estudo, com o intuito de dar conhecimento ao que tem sido pesquisado sobre o tema, apesar de se tratar de um survey, principal limitação da pesquisa; e (iii) o critério utilizado para a identificação e seleção das tendências manifestadas nos diversos artigos foi o material discursivo referente a certas inclinações e a atenção do autor nelas concentrada, o que foi entendido como uma das formas de apontar o(s) foco(s) do artigo. 


\section{DESCRIÇÃO E ANÁLISE DOS DADOS}

A Tabela I apresenta o número de artigos sobre CI da amostra selecionada.

\section{TABELA I}

QUANTIDADE DE ARTIGOS ANALISADOS

\begin{tabular}{|c|c|c|c|c|c|c|c|c|}
\hline \multirow{2}{*}{ FONTE } & \multicolumn{7}{|c|}{ ANO } & \multirow{2}{*}{ TOTAL } \\
\hline & 2000 & 2001 & 2002 & 2003 & 2004 & 2005 & 2006 & \\
\hline Periódicos & 0 & 4 & 4 & 4 & 1 & 3 & 5 & 21 \\
\hline EnAnpad & 1 & 2 & 1 & 7 & 10 & 10 & 4 & 35 \\
\hline Congresso USP & - & 1 & 3 & 0 & 4 & 2 & 7 & 17 \\
\hline TOTAL & 1 & 7 & 8 & 11 & 15 & 15 & 16 & 73 \\
\hline
\end{tabular}

Conforme Tabela I, o EnAnpad é a fonte com maior número de publicações sobre o tema. Pode-se afirmar que há uma tendência de crescimento de pesquisas, uma vez que nos anos de 2005 e 2006 foram publicados I5 e i6 artigos, respectivamente. Entretanto, revela-se que, dentre os 2I artigos de periódicos, 8 são versões anteriormente publicadas no EnAnpad, apresentando variação no que diz respeito a título e autoria. Foi identificado, ainda, um artigo coincidente no EnAnpad e no Congresso USP, e um outro publicado tanto na REAd quanto na O\&S. Nesses casos, foi desconsiderado o último artigo idêntico publicado.

\subsection{ESTUDO BIBLIOMÉTRICO}

Para melhor entendimento dos resultados, os dados demográficos foram agrupados em tabelas, quadros e gráficos, segundo os aspectos apontados na Seção 3 .

\subsubsection{Natureza do estudo}

A classificação dos artigos quanto à natureza do estudo é apresentada na Tabela 2.

Em linhas gerais, os artigos relacionados ao tema são, em sua maioria, práticos (55), e os estudos dos periódicos e do Congresso USP estão divididos 
em estudos de caso e pesquisas survey; dentre os artigos do EnAnpad, predominam pesquisas do tipo survey. Ressalta-se que não foram encontradas pesquisas do tipo experimental, e, dentre os estudos teóricos, prevalecem os do tipo ilustrativo.

\section{TABELA 2}

\section{CLASSIFICAÇÃO DOS ARTIGOS SEGUNDO}

A NATUREZA DO ESTUDO

\begin{tabular}{lcccc}
\multicolumn{1}{r}{ CLASSIFICAÇÃO } & PERIÓDICOS & ENANPAD & CONGRESSO USP & TOTAL \\
\hline ESTUDOS TEÓRICOS & 6 & 7 & 5 & 18 \\
\hline Conceitual & 1 & 0 & 2 & 3 \\
\hline llustrativo & 4 & 4 & 3 & 11 \\
\hline Conceitual aplicado & 1 & 3 & 0 & 4 \\
\hline ESTUDOS PRÁtICOS & 15 & 28 & 12 & 55 \\
\hline Estudo de caso & 6 & 7 & 6 & 19 \\
\hline Survey & 9 & 21 & 6 & 36 \\
\hline Experimental & 0 & 0 & 0 & 0 \\
\hline TOTAL & 21 & 35 & 17 & 73 \\
\hline
\end{tabular}

\subsubsection{Fonte de coleta de dados}

A Tabela 3 evidencia a fonte de coleta de dados utilizada nos 55 estudos classificados como práticos (ver Tabela 2).

\section{TABELA 3}

CLASSIFICAÇÃO DE ACORDO COM A FONTE

DE COLETA DE DADOS

\begin{tabular}{lcccc}
\hline \multirow{2}{*}{ FONTE } & \multicolumn{4}{c}{ DADOS } \\
\cline { 2 - 4 } & PRIMÁRIOS & SECUNDÁRIOS & PRIMÁRIOS E SECUNDÁRIOS & \\
\hline Periódicos & 8 & 4 & 3 & 15 \\
\hline EnAnpad & 15 & 11 & 2 & 28 \\
\hline Congresso USP & 1 & 8 & 3 & 12 \\
\hline TOTAL & 24 & 23 & 8 & 55 \\
\hline
\end{tabular}


Pode-se perceber um relativo equilíbrio entre a utilização de dados primários $(43,64 \%)$ e secundários (4I,82\%). Nas revistas, verifica-se que os dados foram coletados, principalmente com fontes primárias, especialmente por meio de entrevistas e questionários; diferentemente do Congresso USP, em que as pesquisas empíricas foram desenvolvidas, basicamente, com dados secundários, especialmente demonstrações e outros relatórios contábeis, em razão, possivelmente, de ser um evento da área contábil.

\subsubsection{Esfera e nacionalidade}

A classificação dos artigos práticos, quanto à esfera e nacionalidade da empresa em que o estudo empírico foi realizado, é demonstrada na Tabela 4.

TABELA 4

CLASSIFICAÇÃO DOS ARTIGOS QUANTO A ESFERA E NACIONALIDADE DAS EMPRESAS

\begin{tabular}{lcccccc}
\hline & \multicolumn{5}{c}{ ESFERA } & \multicolumn{5}{c}{ NACIONALIDADE } \\
\cline { 2 - 7 } FONTE & Privada & Pública & $\begin{array}{c}\text { Pública/ } \\
\text { privada }\end{array}$ & Brasileira & Internacional & $\begin{array}{l}\text { Brasileira/ } \\
\text { internacional }\end{array}$ \\
\hline Periódicos & 6 & 3 & 5 & 11 & 3 & 1 \\
\hline EnAnpad & 7 & 2 & 13 & 25 & 1 & 2 \\
\hline Congresso USP & 4 & 2 & 5 & 8 & 2 & 2 \\
\hline TOTAL & 17 & 7 & 23 & 44 & 6 & 5 \\
\hline
\end{tabular}

Ressalta-se que, dentre os 55 artigos práticos, apenas um foi realizado em uma organização do terceiro setor. Além disso, em sete estudos, não foi possível identificar a esfera em que se insere a empresa analisada, já que a investigação foi realizada com um grupo aleatório de estudantes, gestores, clientes e funcionários.

Em linhas gerais, pode-se verificar que aproximadamente $42 \%$ dos artigos práticos foram aplicados em empresas da esfera pública/privada, o que pode estar relacionado ao expressivo número de pesquisas survey. Dentre os setores de aplicação das pesquisas, citam-se: tecnologia, ensino, área têxtil, área financeira e turismo. Em relação à nacionalidade, a brasileira representa $80 \%$ das empresas estudadas. Entretanto, destaca-se que, em $20 \%$, foi utilizada, pelo menos, uma empresa internacional no estudo. 


\subsubsection{Abordagem metodológica}

A Tabela 5 exibe a abordagem metodológica utilizada pelos 55 artigos práticos.

\section{TABELA 5}

ABORDAGEM METODOLÓGICA UTILIZADA NOS ARTIGOS

\begin{tabular}{lcccc}
\hline \multirow{2}{*}{ FONTE } & \multicolumn{3}{c}{ ABORDAGEM } & \multirow{2}{*}{ TOTAL } \\
\cline { 2 - 4 } & QUALITATIVA & QUANTITATIVA & QUALI-QUANTITATIVA & \\
\hline Periódicos & 6 & 3 & 6 & 15 \\
\hline EnAnpad & 7 & 11 & 10 & 28 \\
\hline Congresso USP & 6 & 3 & 3 & 12 \\
\hline TOTAL & 19 & 17 & 19 & 55 \\
\hline
\end{tabular}

Não foram identificadas diferenças relevantes quanto à abordagem metodológica, uma vez que se verifica equilíbrio entre estudos qualitativos e estudos qualitativo-quantitativos.

\subsubsection{Número de autores por artigo}

O percentual de artigos por um, dois e três ou mais autores é destacado na Figura I.

\section{FIGURA I}

\section{NÚMERO DE AUTORES POR ARTIGO}

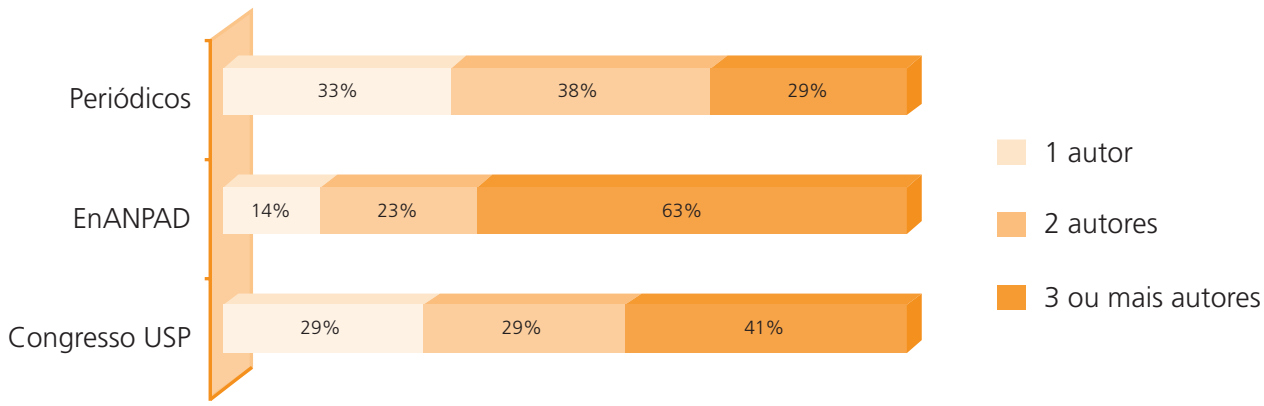

A Figura I evidencia que a maior parte dos artigos do EnAnpad e do Congresso USP foi desenvolvida por três ou mais autores. Entretanto, tal resultado não foi constatado nos artigos de periódicos, em que $33 \%$ e $38 \%$ dos estudos 
foram, respectivamente, elaborados por um autor e dois autores. Tal fato corrobora os resultados do estudo na área de finanças, de Leal, Oliveira e Soluri (2003), que constataram que, nos periódicos, a ocorrência de autor único é mais freqüente do que nos anais.

\subsubsection{Autores mais prolíficos na área de $\mathrm{Cl}$}

O Quadro I exibe um ranking dos autores mais prolíficos na área de CI, bem como as IES, UF e o departamento de afiliação destes.

\section{QUADRO I}

RANKING DOS AUTORES MAIS PROLÍFICOS

\begin{tabular}{|c|c|c|c|c|}
\hline RANKING & $N^{\circ}$ DE PUBLICAÇÕES & AUTOR & $\mathrm{IES} / \mathrm{UF}$ & DEPARTAMENTO \\
\hline \multirow{4}{*}{$1^{\circ}$} & \multirow{4}{*}{5} & ANTUNES, M. T. P. & $\begin{array}{l}\text { Mackenzie/SP } \\
\text { Faap/SP }\end{array}$ & $\begin{array}{l}\text { Contabilidade } \\
\text { Economia }\end{array}$ \\
\hline & & BILICH, F. & $\begin{array}{l}\text { FGV/DF } \\
\text { UNB/DF }\end{array}$ & $\begin{array}{l}\text { Administração } \\
\text { Ciências Agrárias }\end{array}$ \\
\hline & & DASILVA, R. G. & $\begin{array}{l}\text { UNB/DF } \\
\text { UCB/DF }\end{array}$ & Administração \\
\hline & & KAYO, E. K. & Mackenzie/SP & Administração \\
\hline $2^{\circ}$ & 4 & BASSO, L. F. C. & Mackenzie/SP & $\begin{array}{l}\text { Administração } \\
\text { Economia }\end{array}$ \\
\hline \multirow[t]{2}{*}{$3^{\circ}$} & \multirow[t]{2}{*}{3} & PONTE, V. M. R. & Unifor/CE & $\begin{array}{l}\text { Administração } \\
\text { Contabilidade }\end{array}$ \\
\hline & & RAMOS, P. C. S. & - & - \\
\hline
\end{tabular}

Os autores com o maior número de publicações são Kayo, Bilich, Antunes e Dasilva. Vale ressaltar que, dentre esses quatro autores, dois (Bilich e Dasilva) foram co-autores em várias obras que estudam avaliação, mensuração e otimização de AI, especialmente por meio da utilização de método de apoio multicritério. Constata-se que a maior parte dos autores é afiliada à Universidade Presbiteriana Mackenzie; que os autores mais prolíficos têm vínculo com IES de São Paulo (3), do Distrito Federal (2) e do Ceará (I); e que a maioria dos autores pertence ao departamento de Administração, seguido pelo de Contabilidade e Economia. 
4.1.7 IES, UF e departamento de afiliação dos pesquisadores com publicação em $\mathrm{Cl}$

Os quadros 2 e 3 expõem, respectivamente, o ranking das IES e das UF, considerando todos os autores com publicação nos fóruns de pesquisa analisados.

\section{QUADRO 2}

RANKING DAS IES DE VÍNCULO DOS AUTORES

\begin{tabular}{clc}
\hline RANKING & \multicolumn{1}{c}{ IES } & No DE AUTORES \\
\hline $1^{\circ}$ & Mackenzie/SP & 27 \\
\hline $2^{\circ}$ & USP/SP & 19 \\
\hline $3^{\circ}$ & $\begin{array}{l}\text { Unifin/RS } \\
\text { UNB/DF }\end{array}$ & 15 \\
\hline $4^{\circ}$ & UFRGS/RS & 11 \\
\hline
\end{tabular}

Verifica-se que a IES com o maior número de autores que publicaram estudos sobre CI é o Mackenzie/SP (27). É provável que tal fato esteja associado à existência da linha de pesquisa ou área de concentração Finanças estratégicas do Programa de Pós-Graduação em Administração, a qual possui o tema específico Gestão e avaliação de ativos intangíveis.

\section{QUADRO 3}

RANKING UF DE VÍNCULO DOS AUTORES

\begin{tabular}{clc}
\hline RANKING & \multicolumn{1}{c}{ UF } & N DE AUTORES \\
\hline $1^{\circ}$ & São Paulo & 49 \\
\hline $2^{\circ}$ & Rio Grande do Sul & 26 \\
\hline $3^{\circ}$ & Rio de Janeiro & 18 \\
\hline $4^{\circ}$ & Distrito Federal & 17 \\
\hline $5^{\circ}$ & Ceará & 14 \\
\hline $6^{\circ}$ & Santa Catarina & 12 \\
\hline $7^{\circ}$ & Minas Gerais & 10 \\
\hline
\end{tabular}


Os dados do Quadro 3 confirmam o potencial de São Paulo, Rio Grande do Sul, Rio de Janeiro e Distrito Federal, possivelmente porque essas UF, notadamente proeminentes, possuem cursos de pós-graduação stricto sensu em Administração e em Contabilidade.

Distribuindo-se as autorias por regiões do país, foram obtidos os seguintes resultados: Sudeste (47,88\%), Sul $(25,45 \%)$, Nordeste (15,76\%), Centro-Oeste (เo,30\%) e Norte (o,6r\%). Destaca-se que dois autores têm vínculo com instituições de outros países (México e Espanha).

Verificou-se, ainda, que a maior parte dos pesquisadores da área de CI está vinculada aos departamentos de Administração (96 autores), em seguida os de Contabilidade (65), Economia (I7) e Engenharia de Produção (I3). Destacam-se outras áreas de vínculo institucional, como Sociologia, Antropologia, Direito, Ciências Agrárias, Agronegócios, Engenharia e Gestão do Conhecimento, Filosofia, Design e Turismo.

\subsubsection{Obras mais citadas}

As obras mais citadas nos fóruns analisados são apresentadas no Quadro 4.

QUADRO 4

\section{OBRAS MAIS CITADAS}

\begin{tabular}{cll}
\hline FREQÜÊNCIA & \multicolumn{1}{c}{ OBRA } & \multicolumn{1}{c}{ AUTOR (ES) / ANO } \\
\hline 34 & $\begin{array}{l}\text { Capital intelectual: descobrindo o valor real de } \\
\text { sua empresa pela identificação de seus valores } \\
\text { internos (edição em inglês/português) }\end{array}$ & $\begin{array}{l}\text { Edvinsson e Malone } \\
(1997 / 1998)\end{array}$ \\
\hline 34 & $\begin{array}{l}\text { A nova riqueza das organizações } \\
\text { (edição em inglês/português) }\end{array}$ & Sveiby (1997/1998) \\
\hline 27 & $\begin{array}{l}\text { Capital intelectual: a nova vantagem } \\
\text { competitiva das empresas }\end{array}$ & Stewart (1998) \\
\hline 14 & Capital intelectual & Brooking (1996) \\
\hline 13 & $\begin{array}{l}\text { Capital intelectual } \\
\text { reporting }\end{array}$ & Antunes (2000) \\
\hline 11 & Criação de conhecimento na organização & Lonaka e Takeuchi (1997) \\
\hline 10 & $\begin{array}{l}\text { The wealth of knowledge: intellectual capital } \\
\text { and twenty-first century organization }\end{array}$ & Stewart (2001) \\
\hline
\end{tabular}


A análise das informações, disponibilizadas no Quadro 4, permite verificar que as obras Capital intelectual: descobrindo o valor real de sua empresa pela identificação de seus valores internos, de Edvinsson e Malone, e A nova riqueza das organizações, de Sveiby, foram as mais citadas. Dentre as obras mais citadas, os autores Edvisson e Malone, Sveiby, Stewart e Brooking, clássicos na área, são os mais referenciados.

Paralelamente à análise das obras mais citadas, efetuou-se uma análise das fontes de referências sobre CI, em que foi possível constatar a utilização de 2II referências na produção dos 73 artigos analisados, sendo 56 sobre ativos intangíveis, I34 com foco em capital humano e 2I referentes à propriedade intelectual.

\subsection{MAPEAMENTO}

Os resultados do mapeamento, obtidos por meio da análise de conteúdo dos artigos, foram agrupados em tabelas e quadros, segundo os aspectos apontados na Seção 3 .

\subsubsection{Usuários para quem o $\mathrm{Cl}$ é destinado}

A Tabela 6 exibe o público-alvo do CI nas publicações analisadas.

\section{TABELA 6}

PÚBLICO-ALVO DO CI NAS PUBLICAÇÕES SOBRE CI

PÚBLICO-ALVO DO CI

\section{PUBLICAÇÕES}

\begin{tabular}{|c|c|c|c|c|}
\hline \multirow{2}{*}{ PÚBLICO-ALVO DO CI } & \\
\hline & PERIÓDICOS & ENANPAD & CONG. USP & TOTAL \\
\hline Usuários internos & 14 & 18 & 3 & 35 \\
\hline Usuários externos & 3 & 11 & 8 & 22 \\
\hline Usuários internos e externos & 4 & 6 & 6 & 16 \\
\hline TOTAL & 21 & 35 & 17 & 73 \\
\hline
\end{tabular}

O exame dos dados da Tabela 6 indica que a maioria dos artigos é direcionada a usuários internos, sendo assim vinculada ao aspecto gerencial, uma vez que grande parte dos estudos dos periódicos e do EnAnpad concentrou a atenção nesse tipo de público. No Congresso USP de Controladoria e Contabilidade, por sua vez, há predominância de artigos com foco nos usuários externos, especialmente relacionados à evidenciação contábil dos recursos intangíveis aos stakeholders. 


\subsubsection{Enfoque da pesquisa quanto ao $\mathrm{Cl}$}

Os principais enfoques observados são apresentados na Tabela 7.

TABELA 7

ENFOQUE DA PESQUISA QUANTO AO CI

\begin{tabular}{lcccc}
\hline \multirow{2}{*}{ FOCO DO Cl } & \multicolumn{4}{c}{ PUBLICAÇÕES } \\
\cline { 2 - 5 } & PERIÓDICOS & ENANPAD & CONG. USP & TOTAL \\
\hline Gerenciamento/otimização e mensuração & 8 & 7 & 5 & 20 \\
\hline $\begin{array}{l}\text { Reconhec. e contabilização/assimetria } \\
\text { informacional }\end{array}$ & 2 & 6 & 6 & 14 \\
\hline Influência no desempenho econômico-financeiro & 2 & 7 & 2 & 11 \\
\hline O capital humano como fator estratégico & 2 & 6 & 1 & 9 \\
\hline $\begin{array}{l}\text { Gerenciamento/mensuração com método } \\
\text { multicritério }\end{array}$ & 3 & 3 & 0 & 6 \\
\hline Evidenciação & 0 & 1 & 3 & 4 \\
\hline Proteção à propriedade intelectual & 2 & 2 & 0 & 4 \\
\hline Teoria do capital humano & 1 & 2 & 0 & 3 \\
\hline Influência na estrutura de capital empresarial & 1 & 1 & 0 & 2 \\
\hline TOTAL & 21 & 35 & 17 & 73 \\
\hline
\end{tabular}

Os temas gerenciamento/otimização e mensuração, reconhecimento e contabilização/assimetria informacional e influência no desempenho econômico-financeiro, que representam em conjunto 6I,64\% do total de publicações, são direcionados aos usuários internos, corroborando os resultados apresentados na Tabela 6.

É interessante ressaltar que o aspecto mensuração emerge em dois agrupamentos de enfoques - gerenciamento/otimização e mensuração, abordados em 20 artigos (27,40\%), e gerenciamento/mensuração com método multicritério, abordado em seis artigos $(8,22 \%)$-, o que evidencia um movimento de inclusão dessa preocupação entre os tópicos que merecem a atenção da pesquisa na área.

O resultado do enquadramento das produções científicas sobre CI analisadas em enfoques, apresentado na Tabela 7 , revela o caráter multidisciplinar da área, preconizado pela teoria. Percebe-se coincidência de enfoque entre as pesquisas brasileiras e as internacionais, conforme discutido na Seção 2, do presente artigo. 


\subsubsection{0s frameworks de categorias do $\mathrm{Cl}$}

A Tabela 8 evidencia os frameworks de categorias do CI identificados.

\section{TABELA 8}

FRAMEWORKS DE CATEGORIAS DO CI EMPREGADAS

\begin{tabular}{|c|c|c|c|c|}
\hline \multirow{2}{*}{ FRAMEWORKS DE CATEGORIAS DO CI } & \multicolumn{4}{|c|}{ PUBLICAÇÕES } \\
\hline & PERIÓDICOS & ENANPAD & CONG. USP & TOTAL \\
\hline Capital humano, estrutural e de clientes & 10 & 13 & 12 & 35 \\
\hline Capital humano & 4 & 11 & 1 & 16 \\
\hline $\begin{array}{l}\text { Capital humano, estrutural, de clientes } \\
\text { e financeiro }\end{array}$ & 3 & 4 & 2 & 9 \\
\hline Propriedade intelectual & 3 & 3 & 0 & 6 \\
\hline $\begin{array}{l}\text { Capital humano, estrutural, de clientes, } \\
\text { financeiro e resp. socioambiental }\end{array}$ & 1 & 2 & 2 & 5 \\
\hline Recursos de infra-estrutura/cultura corporativa & 0 & 2 & 0 & 2 \\
\hline TOTAL & 21 & 35 & 17 & 73 \\
\hline
\end{tabular}

Verifica-se que o framework de categoria capital humano, estrutural e de clientes foi o mais utilizado nas publicações, seguido da categoria capital humano; a categoria menos utilizada foi recursos de infra-estrutura/cultura corporativa. Em relação à categoria capital humano, estrutural, de clientes, financeiro e responsabilidade socioambiental, destaca-se que os cinco artigos foram publicados a partir do ano de 2004 , o que pode demonstrar uma interconexão do CI com a área socioambiental.

\subsubsection{Modelos/autores e pronunciamentos norteadores}

A Tabela 9 apresenta os modelos/autores e pronunciamentos de CI norteadores dos artigos analisados.

O modelo mais utilizado foi o de Edvinsson e Malone; os modelos de Sveiby e de Stewart demonstram ter um grau de atratividade similar entre os pesquisadores de CI. No entanto, essa constatação diverge dos resultados do estudo feito no contexto internacional, de Carvalho e Ensslin (2006), o qual conclui que há uma tendência a aceitar o framework de classificação de Sveiby (I997).

No que diz respeito à utilização dos pronunciamentos do Financial Accounting Standards Board (Fasb), FAS n ${ }^{\circ}$ I42/OI e SFAC n ${ }^{\circ}$ 7/00, esses foram base 
apenas para quatro artigos do EnAnpad, que trataram da mensuração a valor justo (fair value) e da contabilização (teste de impairment) dos AI.

\section{TABELA 9}

PRINCIPAIS MODELOS/AUTORES

E PRONUNCIAMENTOS DE CI

\begin{tabular}{lcccc}
\hline \multirow{2}{*}{ PRINCIPAIS MODELOS/AUTORES/PRONUNCIAMENTOS S } & \multicolumn{4}{c}{ PUBLICAÇÕES } \\
\cline { 2 - 5 } & PERIÓDICOS & ENANPAD & CONG. USP & TOTAL \\
\hline Edvinsson e Malone (1997) & 7 & 5 & 7 & 19 \\
\hline Sveiby (1997) & 3 & 4 & 4 & 11 \\
\hline Stewart (1998) & 3 & 3 & 4 & 10 \\
\hline Brooking (1996) & 1 & 3 & 1 & 5 \\
\hline Pronunc. FAS n' 142/01 e SFAC n' 7/00 - FASB & 0 & 4 & 0 & 4 \\
\hline TOTAL & 14 & 19 & 16 & 49 \\
\hline
\end{tabular}

\subsubsection{Principais tendências manifestadas nos estudos de Cl}

No Quadro 5, podem ser observadas as principais tendências identificadas por meio do critério utilizado, qual seja: o material discursivo referente a certas inclinações e a atenção do autor nelas concentrada. Esse procedimento foi realizado por meio da análise do conteúdo dos textos (comunicações), com base na definição da análise do conteúdo proposta por Bardin (2004), o que permitiu que os autores do presente artigo formulassem algumas tendências.

A análise das informações disponibilizadas no Quadro 5 permite verificar as principais tendências identificadas: reconhecimento, contabilização e mensuração do AI; gerenciamento do CI; importância do capital humano; relação do CI com o desempenho econômico; teoria do capital humano; propriedade intelectual; relação entre CI e TI; e relação do CI com o endividamento. Tais tendências ratificam as observações de Kaufmann e Schmeider (2004) quanto à caracterização de CI por uma variedade de visões e interpretações, o que aponta para a necessidade do estabelecimento de uma linguagem conceitual a ser compartilhada pela comunidade científica.

Pode-se observar, ainda, que as Tendências 1 e 2 foram as mais ocorrentes, totalizando 35 das 73 publicações analisadas. Por sua vez, as Tendências 7 e 8 emergiram em poucas publicações, talvez porque os temas "tecnologia da informação" e "endividamento" sejam mais específicos do campo de conhecimento em que ocorrem. 


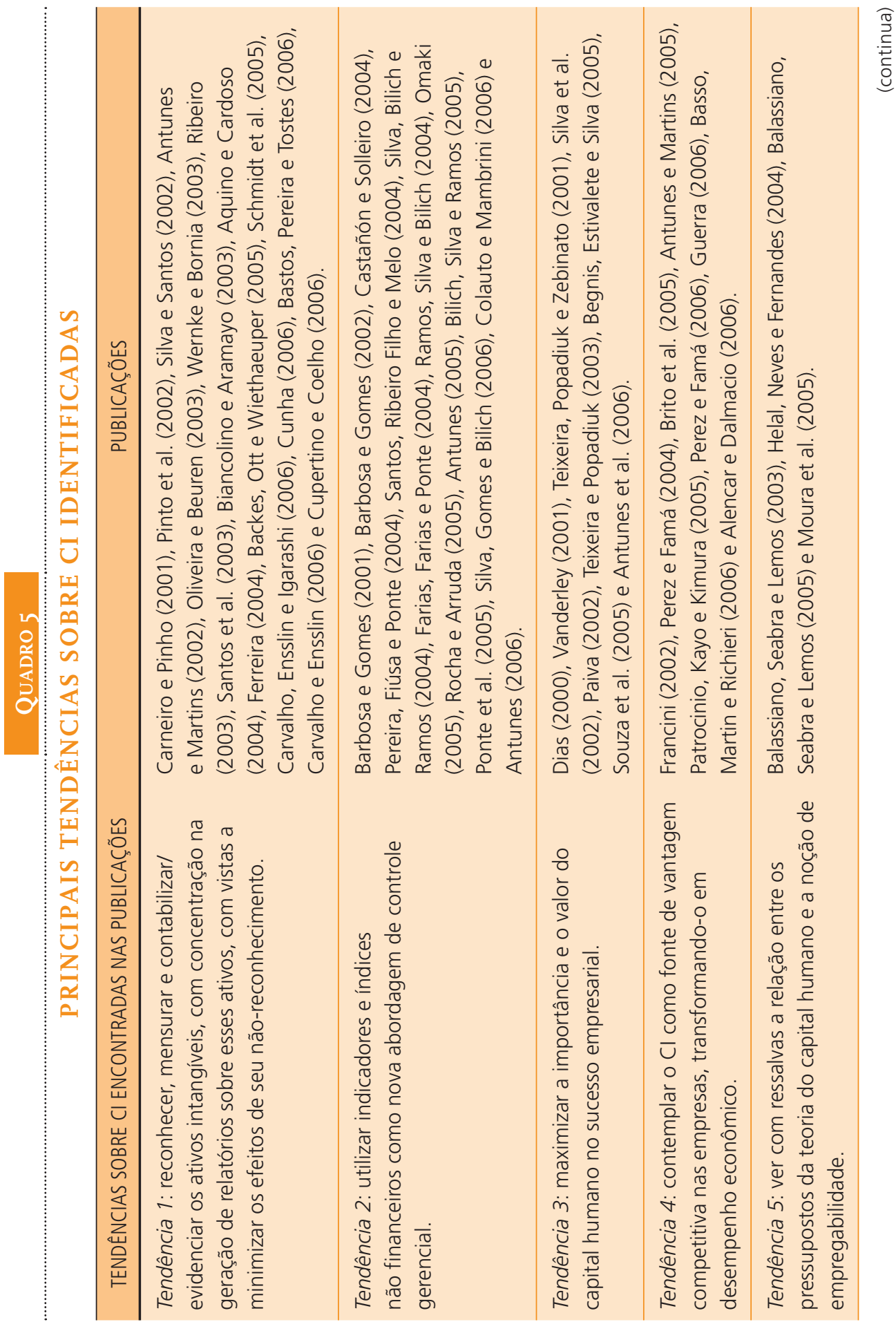




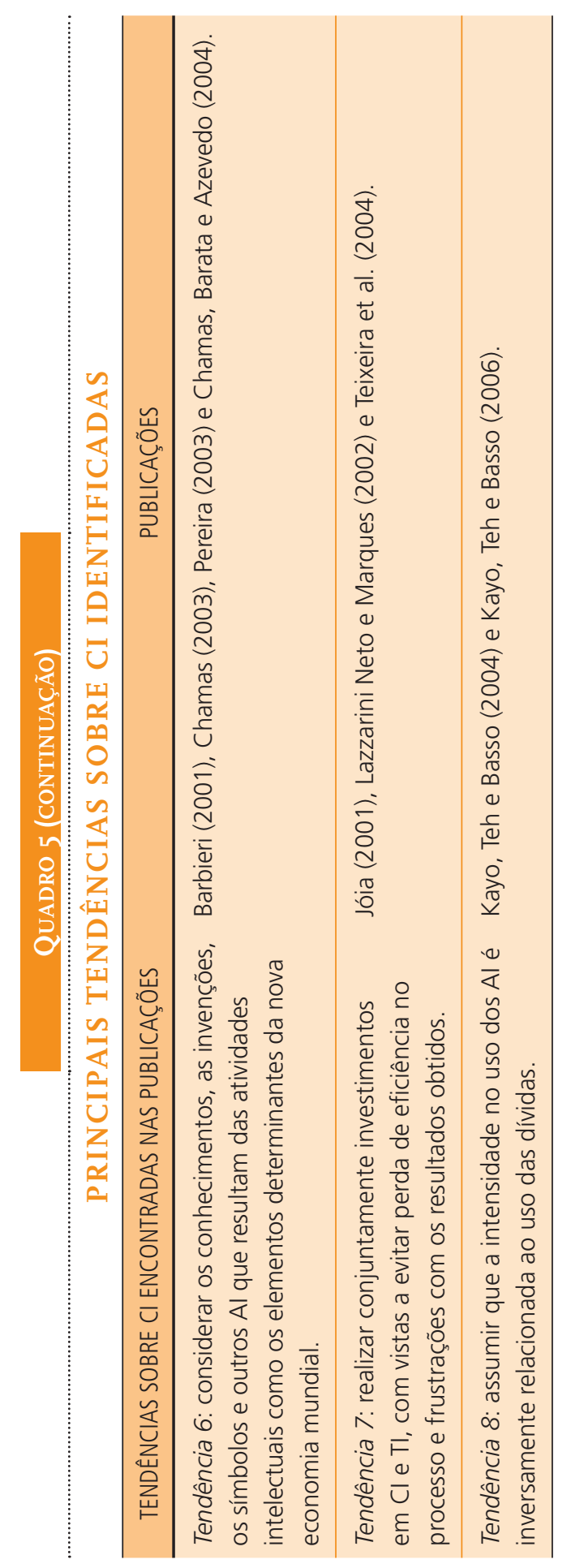


- UM ESTUDO REFLEXIVO DA PRODUÇÃO CIENTÍFICA EM CAPITAL INTELECTUAL •

ALESSANDRA V. GALLON • FLÁVIA C. DE SOUZA • SULIANI ROVER • SANDRA R. ENSSLIN

\subsubsection{Principais resultados dos modelos de mensuração de $\mathrm{Cl}$ propostos}

Os principais resultados das pesquisas são apresentados no Quadro 6 .

\section{QUADRO 6}

RESULTADOS RELACIONADOS A PROPOSIÇÕES DE MODELO DE MENSURAÇÃO DO CI

\begin{tabular}{lll}
\hline \multicolumn{1}{c}{ PERIÓDICOS } & \multicolumn{1}{c}{ ENANPAD } & \multicolumn{1}{c}{ CONGRESSO USP } \\
\hline Resultado 1: o Mapa para & Resultado 1: a aplicação & Resultado 1: o modelo \\
Identificação de Potenciais & do método Electre TRI & G-Mapa IC permitiu \\
Geradores de Intangíveis & não apenas possibilitou & obter aproximações \\
contribuiu para a análise e & a mensuração dos Al, & da realidade em alta \\
tomada de decisões empresariais & como também possibilitou & dimensão. Foi proposto \\
(WERNKE; BORNIA, 2003). & prescrever políticas para & um sistema de visualização \\
Resultado 2: o Electre TRI mostrou- & otimização dos Al, como & de desempenho, que dá \\
se adaptado à avaliação de Cl, & e onde a empresa deve & suporte à interpretação da \\
pois permitiu as comparações de & investir com um mínimo & interpolação dos dados de \\
padrões previamente definidos & de esforço (SILVA; BILICH; & alta dimensão (SANTOS; \\
e a incorporação de um grande & RAMOS, 2004). & RIBEIRO FILHO; MELO, \\
número de variáveis no processo & Resultado 2: ficou & 2004). \\
de avaliação (BILICH; SILVA; & comprovada a pertinência & Resultado 2: a proposição \\
RAMOS, 2005). & da aplicabilidade de & de indicadores viabilizou \\
Resultado 3: foi comprovada & métodos multicritérios na & o monitoramento dos \\
a pertinência da aplicabilidade & avaliação e mensuração do & investimentos que \\
de métodos na avaliação e & conhecimento e da política & compõem o CI nas IES \\
mensuração de AI (SILVA et al., & de inovação (RAMOS; & privadas (COLAUTO; \\
2002). & SILVA; BILICH, 2004). & MAMBRINI, 2006). \\
\hline
\end{tabular}

Verifica-se, com base na análise geral das pesquisas que propuseram modelo de mensuração do CI, que seus resultados contribuíram para o avanço dos estudos sobre o tema, em todos os aspectos apontados no Quadro 6, mesmo com as limitações percebidas pelos autores do presente artigo, quais sejam: não-cobertura de todos os fatores intangíveis e dificuldade de obtenção dos dados (WERNKE; BORNIA, 2003); e não-consideração de todos os indicadores possíveis para avaliar os AI (COLAUTO; MAMBRINI, 2006).

\subsubsection{Principais resultados oriundos das pesquisas empíricas}

O Quadro 7 exibe alguns resultados relacionados às pesquisas empíricas sobre CI. 


\section{QUADRO 7}

RESULTADOS RELACIONADOS A PESQUISAS EMPÍRICAS SOBRE CI

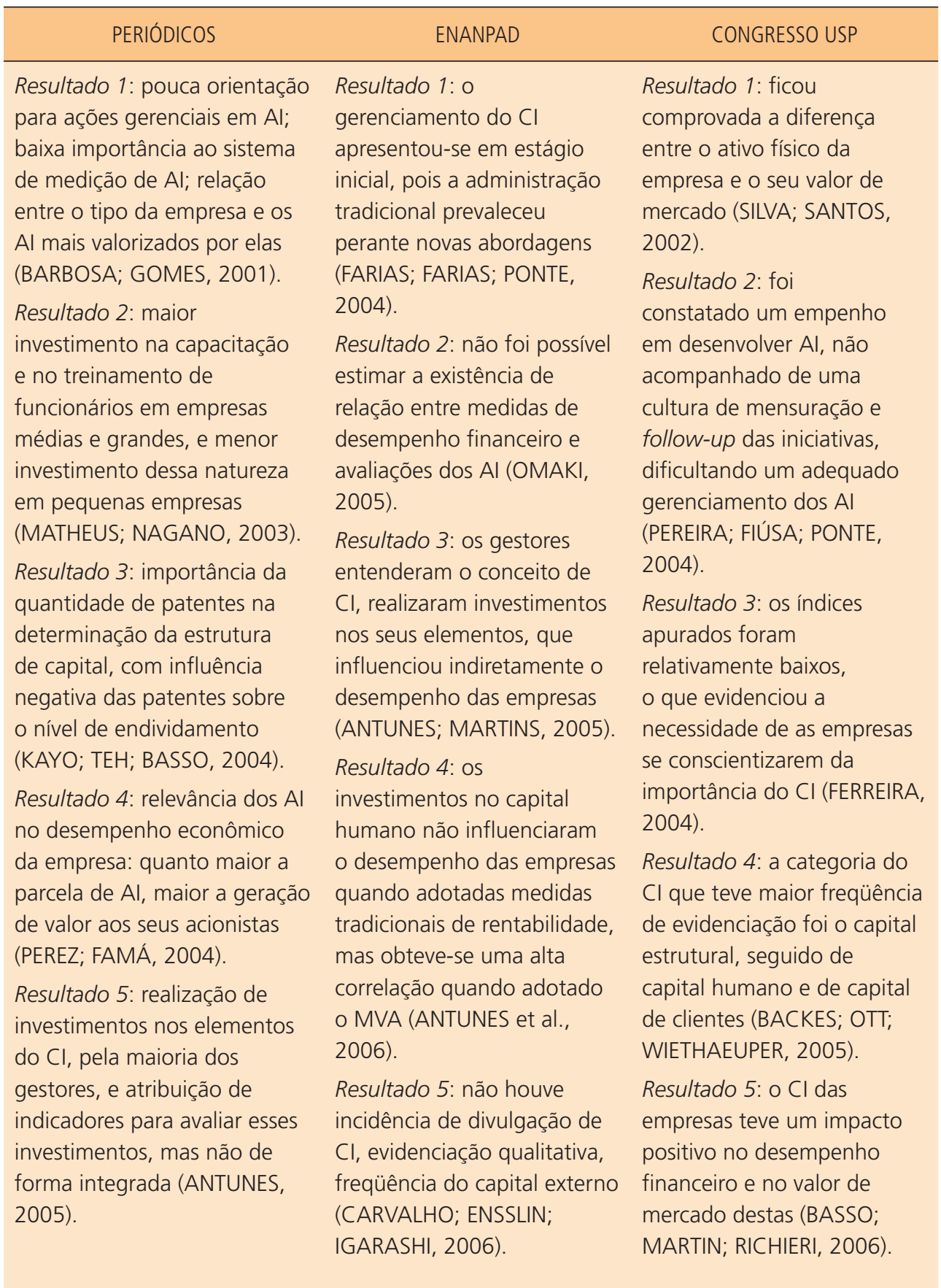


Sobre os resultados das pesquisas empíricas, verifica-se: (i) gerenciamento do CI - o Resultado 1 do EnAnpad e os Resultados 1 e 5 das revistas são semelhantes, por constatarem que o gerenciamento do CI ainda é incipiente, embora o Resultado 3 do EnAnpad tenha constatado que o CI encontra-se em um estágio evoluído; (ii) desempenho econômico - os Resultados 3 e 5 do Congresso USP e o Resultado 4 das revistas demonstraram uma relação positiva entre os investimentos em AI e o desempenho financeiro, embora os Resultados 2 e 4 do EnAnpad se contraponham a essa relação; e (iii) evidenciação - o Resultado 4 do Congresso USP demonstrou maior evidenciação da categoria "capital estrutural" nos relatórios da Administração, e o Resultado 5 do EnAnpad, maior evidenciação do "capital externo" em artigos científicos.

\subsubsection{Recomendações para futuras pesquisas em $\mathrm{Cl}$}

É apresentado, no Quadro 8, um resumo das principais recomendações sugeridas.

\section{QuAdro 8}

\section{RECOMENDAÇÕES PARA FUTURAS \\ PESQUISAS SUGERIDAS}

RECOMENDAÇÕES SOBRE PESQUISA EM CI SUGERIDAS NAS PUBLICAÇÕES
PUBLICAÇÕES
Recomendação 1: replicação das pesquisas realizadas em empresas de outros setores e localidades e/ou ampliação do período de análise.
Jóia (2001), Teixeira, Popadiuk e Zebinato (2001), Silva e Santos (2002), Wernke e Bornia (2003); Pereira, Fiúsa e Ponte (2004); Ferreira (2004), Farias, Farias e Ponte (2004), Omaki (2005), Moura et al. (2005), Guerra (2006), Basso, Martin e Richieri (2006), Bastos, Pereira e Tostes (2006), Carvalho e Ensslin (2006) e Cupertino e Coelho (2006).

Recomendação 2: desenvolvimento de novos modelos para avaliação de $\mathrm{Cl}$.

Jóia (2001), Moura et al. (2005), Souza et al. (2005), Basso, Martin e Richieri (2006) e Carvalho e Ensslin, S. (2006).

Recomendação 3: mensuração do Al por meio de escalas com o uso de métodos multicritérios de apoio à decisão.
Wernke e Bornia (2003), Silva et al. (2004), e Ramos, Silva e Bilich (2004). 
Pode-se observar que a Recomendação 1, que trata da replicação das pesquisas em amostras mais amplas e em maior período de tempo, foi, isoladamente, a de maior ocorrência, sendo sugerida continuamente por todo o período analisado. Já as Recomendações 2 e 3, que tratam, em linhas gerais, de modelos de avaliação/ mensuração, ocorrem em nove pesquisas.

\section{CONSIDERAÇÕES FINAIS}

Este estudo objetivou apresentar um estudo reflexivo da produção científica em CI, por meio de um estudo bibliométrico e de um mapeamento das publicações reunidas em periódicos nacionais "A" pela Capes - que regularmente publicam artigos relacionados ao tema - e nos anais do EnAnpad e do Congresso USP, no período de 2000 a 2006.

A leitura que os autores fazem das informações geradas se refere aos resultados advindos do estudo bibliométrico e do mapeamento e aqui apresentada em termos da interpretação dos autores à luz do referencial teórico deste artigo. Justifica-se esta postura, uma vez que as considerações pontuais, a respeito de cada item investigado, foram apresentadas na seção 4.

Quanto aos dados demográficos do estudo bibliométrico, chamou a atenção dos autores o fato de os estudos práticos terem superado, em quantidade, os estudos teóricos. O referencial teórico sinalizou a existência de diferentes visões e interpretações de CI; nesse sentido, esperava-se encontrar um maior número de artigos devotados a reflexões teóricas, explicando as terminologias e definições encontradas, o que não ocorreu. Outro aspecto a ser salientado diz respeito à abordagem metodológica, em relação à emergência da abordagem qualitativa, ante a maior incidência dos estudos práticos.

Quanto ao mapeamento do conteúdo dos artigos, enfatiza-se o fato de os enfoques/temas identificados serem coincidentes com as perspectivas identificadas no contexto internacional (MARR, 2005), o que evidencia um paralelismo entre as preocupações dos pesquisadores brasileiros e internacionais. Quanto às tendências e aos resultados observados, vale salientar que, embora pareça haver uma coincidência das lacunas na pesquisa em CI e a necessidade de desenvolver estudos nessas áreas, os estudos pesquisados parecem ainda não ter uma solução para esses problemas. O que deixa a comunidade científica, que investiga CI, com a questão básica de conceitualizar esse ativo em termos que representem os pesquisadores das várias perspectivas e em termos de uma linguagem comum que permita a conversação teórica na área.

Com base nessas reflexões, entende-se que os achados desta pesquisa apresentam contribuição acadêmica e poderão servir de referência não só para iniciantes, mas também para pesquisadores estabelecidos que venham a se interessar 
pelo quadro geral da pesquisa na área de CI. Como palavra final, recomenda-se uma eventual expansão do estudo ora apresentado, em termos de buscar, com base no material investigado, aproximações conceituais que permitam a construção e o estabelecimento de definições terminológicas.

\section{REFERÊENCIAS}

ALAVI, M.; CARLSON, P. A review os MIS research and disciplinary development. Journal of Management Information Systems, Spring I992, v. 8, n. 4, p. 45-62.

ANTUNES, M. T. P. Capital intelectual. São Paulo: Atlas, 2000.

A controladoria e o capital intelectual: um estudo empírico sobre sua gestão. Revista de Contabilidade \& Finanças - USP, São Paulo, n. 4I, p. 2I-37, maio/ago. 2006.

BARDIN, L. Análise de conteúdo. 3. ed. Lisboa: Edições 70, 2004.

BROOKING, A. Intellectual capital: core asset for the third millennium enterprise. Boston: Thomson Publishing Inc., I996.

CARVALHO, F. N.; ENSSLIN, S. R. A evidenciação voluntária do capital intelectual: um estudo revisionista do contexto internacional. In: Congresso USP de Controladoria e Contabilidade, 7., 2006, São Paulo. Anais ... São Paulo: FEA/USP, 2006. CD-ROM.

COLAUTO, R. D.; MAMBRINI, A. Avaliação do capital intelectual não adquirido: uma proposta para instituição de ensino superior privada. In: Congresso USP de Controladoria e Contabilidade, 7., 2006, São Paulo. Anais ... São Paulo: FEA/USP, 2006. CD-ROM.

EDVINSSON, L.; MALONE, M. S. Capital intelectual. São Paulo: Makron Books, I998.

GUTHRIE, J.; PETTY, R. Intellectual capital literature review: measurement, reporting and management. Journal of Intellectual Capital, Bradford, 2000, v. I, n. 2, p. I55-176.

JUNG, C. G. Estudos experimentais. Petrópolis: Vozes, I997.

KAUFMANN, L.; SCHNEIDER, Y. Intangibles: a synthesis of current research. Journal of Intellectual Capital. Bradford, 2004, v. 5, n. 3, p. 366-388.

KAYO, E. K.; TEH, C. C.; BASSO, L. F. C. A influência dos ativos intangíveis sobre a estrutura de capital. In: ENANPAD, 28., 2004, Curitiba. Anais... Rio de Janeiro: Anpad, 2004. CD-ROM.

LEAL, R. P. C.; OLIVEIRA, J.; SOLURI, A. F. Perfil da pesquisa em finanças no Brasil. Revista de Administração de Empresas, São Paulo, v. 43, n. I, p. 9I-I04, jan./mar. 2003.

LEV, B. Intangibles: management, measurement, and reporting. Washington: Brookings, $200 \mathrm{I}$.

Remarks on the measurement, valuation and reporting odd intangible assets. Economic

Policy Review, p. I7-22, Sept. 2003.

Sharpening the intangibles edge. Harvard Business Review (HBR), Spotlight, p. Io9-II6, June 2004 .

MACIAS-CHAPULA, C. A. O papel da informetria e da cienciometria e sua perspectiva nacional e internacional. Ciência da Informação, Brasília, v. 27, n. 2, p. I34-I40, maio/ago. I998.

MARR, B. Perspectives on intellectual capital: multidisciplinary insights into management, measurement, and reporting. Amsterdam: Elsevier Butterworth-Heinemann, 2005.

MEIRELLES, F. S.; HOPPEN, N. Sistemas de informação: a pesquisa científica brasileira entre I990 e 2003. Revista de Administração de Empresas, São Paulo, v. 45, n. I, p. 338-347, jan./mar. 2005 . 
PABLOS, P. O. Evidence of intellectual capital measurement from Asia, Europe and Middle East. Journal of Intellectual Capital, Denmark, v. 3, n. 3, p. 287-302, 2002.

PEREIRA, M. S.; FIÚSA, J. L. A.; PONTE, V. M. R. Capital intelectual e mensuração: um estudo de caso em uma empresa de telecomunicação. In: CONGRESSO USP DE CONTROLADORIA E CONTABILIDADE, 4., 2004, São Paulo. Anais... São Paulo: FEA/USP, 2004. CD-ROM.

REZENDE, Y. Informação para negócios: os novos agentes do conhecimento e a gestão do capital intelectual. Ciência da Informação, Brasília, v. 3I, n. I, p. 75-83, jan./abr. 2002.

STEWART, T. A. Capital intelectual: a nova vantagem competitiva das empresas. Rio de Janeiro: Campus, I998.

. The wealth of knowledge: intellectual capital and twenty-first century organization. New York: Currency Book, 200I.

TINOCO, R. M.; GONDIM, S. M. G. A avaliação de desempenho em uma universidade pública estadual: com a palavra a comunidade acadêmica. In: ENANPAD, 27., 2003, Curitiba. Anais... Rio de Janeiro: Anpad, 2003. CD-ROM.

TRIPODI, T.; FELLIN, P.; MEYER, H. J. Análise da pesquisa social: diretrizes para o uso de pesquisa em serviço social e ciências sociais. 2. ed. Rio de Janeiro: Francisco Alves, I98I.

WALLMAN, S. M. H. The future of accounting and financial reporting: the colorized approach. The American Institute of Certifies Public Accountants. In: NACIONAL CONFERENCE ON CURRENT SEC DEVELOPMENTS, 23., I996, Washington, DC. Disponível em: <http://www.sec.gov/ news/speech/speecharchive/1996/spcho79.txt>. Acesso em: 7 dez. 2006.

WERNKE, R.; BORNIA, A. C. Estudo de caso aplicando modelo para identificação de potenciais geradores de intangíveis. Revista Contabilidade \& Finanças - USP, São Paulo, n. 33, p. 45-64, set./ dez. 2003 .

YIN, R. K. Estudo de caso: planejamento e métodos. São Paulo: Bookman, 2005.

\section{TRAMITAÇ ÃO}

Recebido em 28/1/2008

Aprovado em 8/4/2008

\section{ARTIGOS SOBRE CAPITAL INTELECTUAL ANALISADOS}

\section{Periódicos}

ANTUNES, M. T. P. A controladoria e o capital intelectual: um estudo empírico sobre sua gestão. RC\&F, 2006.

ANTUNES, M. T. P.; MARTINS, E. Capital intelectual: verdades e mitos. RC\&F, 2002.

BALASSIANO, M.; SEABRA, A. A.; LEMOS, A. H. Escolaridade, salários e empregabilidade: tem razão a teoria do capital humano? RAC, 2005 .

BARBIERI, J. C. Uma avaliação do acordo sobre aspectos dos direitos de propriedade intelectual relacionados com o comércio: cinco anos depois. RAP, $200 \mathrm{I}$. 
BARBOSA, J. G. P. Um estudo exploratório do controle gerencial de ativos e recursos intangíveis em empresas brasileiras. RAC, 2002.

BILICH, F.; DASILVA, R. G.; RAMOS, P. T. C. S. Gestão da inovação de capital intelectual em pesquisa e desenvolvimento. REAd, 2005.

CASTAÑÓN, R.; SOLLEIRO, J. L. Gestão de capital intelectual em centros mexicanos de P\&D. REAd, 2004.

CHAMAS, C. I. Gerenciamento da proteção e exploração econômica da propriedade intelectual. RAP, 2003.

DASILVA, R. G.; GOMES, L. F. A. M.; BILICH, F. Avaliação e otimização de capital intelectual. REAd, 2006.

FRANCINI, W. S. A gestão do conhecimento: conectando estratégia e valor para a empresa. RAE Elet., 2002.

JOIA, L. A. Medindo o capital intelectual. RAE, 200I.

JOIA, L. A. Uso do capital intelectual para avaliação de projetos de tecnologia educacional: o caso Proinfo. RAP, $200 I$.

KAYO, E. K.; TEH, C. C.; BASSO, L. F. C. Ativos intangíveis e estrutura de capital: a influência das marcas e patentes sobre o endividamento. Rausp, 2006.

KAYO, E. K. et al. Ativos intangíveis, ciclo de vida e criação de valor. RAC, 2006.

MATHEUS, L. F.; NAGANO, M. S.; MERLO, E. M. Análise da identificação e da gestão do capital intelectual nas usinas sucroalcooleiras. REAd, 2005.

NETO, S. L.; MARQUES, M. Capital humano e TI gerando vantagem competitiva. RAE Elet., 2002.

OLIVEIRA, J. M. BEUREN, I. M. Tratamento contábil do capital intelectual em empresas com valor de mercado superior ao valor contábil. RC\&F, 2003.

PEREZ, M. M.; FAMÁ, R. Ativos intangíveis e o desempenho empresarial. RC\&F, 2006.

TEIXEIRA, M. L. M.; POPADIUK, S. Confiança e desenvolvimento de capital intelectual: o que os empregados esperam de seus líderes? RAC, 2003.

VANDERLEY, L. G. Capital humano: a vantagem competitiva. O\&S, 200 I.

WERNKE, R. BORNIA, A. C. Estudo de caso aplicando modelo para identificação de potenciais geradores de intangíveis. RC\&F, 2003.

\section{EnAnpad}

ALENCAR, R. C.; DALMÁCIO, F. Z. A relevância da informação contábil no processo de avaliação de empresas brasileiras - uma análise dos investimentos em ativos intangíveis e seus efeitos sobre value-relevance do lucro e patrimônio líquido. 2006.

ANTUNES, M. T. P. A controladoria e o capital intelectual: um estudo empírico sobre a sua gestão. 2005 .

ANTUNES, M. T. P. et al. Estudo sobre divulgação dos investimentos em capital humano (disclosure) e desempenho empresarial. 2006.

ANTUNES, M. T. P.; MARTINS, E. Capital intelectual: seu entendimento e seus impactos no desempenho de grandes empresas brasileiras. 2005.

AQUINO, A. C. B.; CARDOSO, R. L. Ativos especiais: buscando razões econômicas. 2004. 
BALASSIANO, M.; SEABRA, A. A.; LEMOS, A. H. Educação, salários e empregabilidade: tem razão a teoria do capital humano? 2003.

BARBOSA, J. G. P.; GOMES, J. S. Um estudo exploratório do controle gerencial de ativos e recursos intangíveis (capital intelectual) em empresas brasileiras. 200I.

BEGNIS, H. S. M.; ESTIVALETE, V. F. B.; SILVA, T. N. Ensino, pesquisa e capital humano na qualificação de profissionais do agronegócio no Brasil. 2005.

BIANCOLINO, C. A.; ARAMAYO, P. D. Goodwill \& impairment test: considerações sob à luz do US GAAP. 2003.

BRITO, E. P. Z. et al. Reputação corporativa e desempenho: uma análise empírica no setor bancário. 2005 .

CARVALHO, F. N.; ENSSLIN, S. R.; IGARASHI, D. C. C. Evidenciação voluntária do capital intelectual no contexto brasileiro: cotejamento com os contextos internacional e australiano. 2006.

CHAMAS, C. I.; BARATA, M.; AZEVEDO, A. Proteção intelectual de invenções biotecnológicas. 2004 .

DASILVA, R. G. et al. Avaliação, mensuração e otimização de ativos intangíveis: utilização de Método de Apoio Multicritério no capital intelectual. 2002.

DASILVA, R. G.; BILICH, F.; RAMOS, P. T. C. S. Innovation management of intellectual capital: measurement and optimization through Multicriteria Method. 2004.

DIAS, E. L. A importância da gestão do capital humano na indústria do turismo. 2000.

FARIAS, F. S. O.; FARIAS, I. Q.; PONTE, V. M. R. Gerenciamento do capital intelectual: um estudo em empresas do setor têxtil cearense. 2004.

FERNANDES, D. C.; NEVES, J. A. B.; HELAL, D. H. Autoridade e capital humano em organizações centradas no conhecimento: o caso do setor elétrico em Pernambuco. 2004.

HELAL, D. H.; NEVES, J. A. B.; FERNANDES, D. C. Empregabilidade gerencial no Brasil: um estudo longitudinal. 2004.

KAYO, E. K.; TEH, C. C.; BASSO, L. F. C. A influência dos ativos intangíveis sobre a estrutura de capital. 2004.

KAYO, E. K.; BASSO, L. F. C; PENNER-HAHN, J. D. The Value Relevance of Intangible Capabilities Deployment: the Role of Firm Life Cycle. 2006.

MATHEUS, L. F.; NAGANO, M. S. Análise da identificação e da gestão do capital intelectual nas usinas sucroalcooleiras. 2003.

MOURA, S. F. et al. O valor do intangível em Instituições de Ensino Superior: um enfoque no capital humano. 2005 .

OMAKI, E. T. Recursos intangíveis e desempenho em grandes empresas brasileiras: avaliações dos recursos intangíveis como estimador de medidas de desempenho financeiras. 2005.

PATROCINIO, M. R.; KAYO, E. K.; KIMURA, H. Intangibilidade e criação de valor nos eventos de fusão e aquisição: uma análise dos retornos anormais do período de I994 a 2004. 2005.

PEREIRA, J. M. Política de proteção à propriedade intelectual no Brasil. 2003.

PEREZ, M. M.; FAMÁ, R. Características estratégicas dos ativos intangíveis e o desempenho econômico da empresa. 2004 .

ROCHA, S.; ARRUDA, C. Aplicação de ferramenta de medição de capital intelectual em uma empresa industrial. 2005 .

SCHMIDT, P. et al. Evidenciação de ativos intangíveis: uma forma de minimizar os problemas causados pela seleção adversa. 2005 . 
SOUZA, L. L. C. et al. Terceirização estratégica e a gestão do fator humano em grandes indústrias cearenses de confecção. 2005.

RAMOS, P. T. C. S; DASILVA, R. G.; BILICH, F. Análise, avaliação e otimização de inovações no ensino de administração por Método Multicritério. 2004.

RIBEIRO, R. A. S. O ativo intangível e o fair value: reconhecimento, mensuração, relacionamento e legalidade. 2003.

SANTOS, J. L. et al. Ativos intangíveis - teste de impairment. 2003.

SANTOS, J. L. et al. Ativos intangíveis - mensuração do valor justo nas normas internacionais e norte-americanas. 2003.

TEIXEIRA, A. A. C. et al. Tecnologias de informação hospitalar, capital humano, eficiência e qualidade. Um S.O.N.H.O.? 2004.

TEIXEIRA, M. L. M.; POPADIUK, S; ZEBINATO, A. N. Gerenciando confiança para desenvolver capital intelectual: o que os empregados esperam de seus líderes? 200I.

\section{Congresso USP}

BACKES, R. G.; OTT, E.; WIETHAEUPER, D. Informações sobre capital intelectual evidenciadas pelas companhias abertas listadas em nível I de governança corporativa da Bovespa. 2005 .

BASSO, L. F. C.; MARTIN, D. M. L.; RICHIERI, F. O impacto do capital intelectual no desempenho financeiro das empresas brasileiras. 2006.

BASTOS, P. S. S.; PEREIRA, R. M.; TOSTES, F. P. A evidenciação contábil do ativo intangível atletas - dos clubes de futebol. 2006.

CARNEIRO, C. M. B. PINHO, D. R. A mensuração do goodwill em avaliações de empresas: o caso da Companhia Energética do Ceará - Coelce. 200I.

CARVALHO, F. N.; ENSSLIN, S. R. A evidenciação voluntária do capital intelectual: um estudo revisionista do contexto internacional. 2006.

COLAUTO, R. D.; MAMBRINI, A. Avaliação do capital intelectual não adquirido: uma proposta para Instituição de Ensino Superior Privada. 2006.

CUNHA, J. H. C. A contabilidade e o real valor das empresas: foco no capital intelectual. 2006.

CUPERTINO, C. M.; COELHO, R. A. Alavancagem, liquidez, tamanho, risco, imobilizado e intangíveis: um estudo de algumas condicionantes do book-to-market em empresas brasileiras. 2006.

FERREIRA, L. N. Capital intelectual: um estudo exploratório nas empresas de construção civil do Distrito Federal. 2004.

GUERRA, A. R. Goodwill adquirido e sua relação com alguns setores econômicos no Brasil. 2006.

PAIVA, S. B. As novas tendências na área contábil e o foco humano. 2002.

PEREIRA, M. S.; FIÚSA, J. L. A.; PONTE, V. M. R. Capital intelectual e mensuração: um estudo de caso em uma empresa de telecomunicação. 2004.

PINTO, J. G. A. et al. Goodwill: uma abordagem conceitual. 2002.

PONTE, R. C. D. V. et al. O capital intelectual como ferramenta de gestão estratégica: um estudo em empresas ganhadoras do prêmio Delmiro Gouveia 2004. 2005.

QUEIROZ, A. B. El capital intelectual em el sector público. 2004. 
SANTOS, J.; RIBEIRO FILHO, J. F.; MELO, S. B. Evidenciação gráfica de ativos intangíveis em superfície de desempenho: aprimorando o Modelo de Kitts, Edvinsson e Beding - Mapeamento IC. 2004 .

SILVA, A. C.; SANTOS, M. S. A importância dos ativos intangíveis/goodwill na formação do valor de mercado das empresas de internet: um estudo baseado na Companhia Yahoo!. 2002. 